\title{
IMPLEMENTASI WEIGHTED PRODUCT UNTUK MEMBERIKAN REKOMENDASI PROSPEK PELANGGAN BAGI SALES MARKETING BERDASARKAN WEB ANALYTICS
}

\author{
Fajar Pradana*1, Fitra A. Bachtiar ${ }^{2}$, Mochammad Dearifaldi Al Ikhsan ${ }^{3}$ \\ ${ }^{1,2,3}$ Universitas Brawijaya \\ ${ }^{1}$ fajar.p@ub.ac.id, ${ }^{2}$ fitra.bachtiar@ub.ac.id, ${ }^{3}$ aldi_ikhsan98@live.com \\ *Penulis Korespondensi
}

(Naskah masuk: 17 Oktober 2019, diterima untuk diterbitkan: 10 Februari 2020)

\begin{abstract}
Abstrak
Keberhasilan sebuah perusahaan dalam memasarkan produk atau jasa yang ditawarkan sangat tergantung dari kinerja marketing. Kegiatan marketing saat ini berkembang tidak hanya dilakukan secara kovensional melalui tatap muka langsung dengan pelanggan. Salah satu pemasaran yang dilakukan pada perusahaan adalah dengan digital marketing. Digital marketing menggunakan Internet dan World Wide Web untuk mendekati pelanggan. Dalam mencapai tujuan ini, perusahaan harus mengadopsi Web analytics, yang didefinisikan sebagai pengukuran, pengumpulan, analisis dan pelaporan data Internet untuk tujuan memahami dan mengoptimalkan penggunaan Web. Dengan melakukan web analytics, marketing dapat mengenali calon pelanggan prospek yang sering mengakses website perusahaan. Tidak seperti kegiatan marketing konvensional, kegiatan mengenali pengunjung website menjadi kesulitan tersendiri. Pada penelitian ini akan dilakukan penggalian data lebih dalam untuk melihat perilaku dari pengunjung website dari sebuah perusahaan dengan menggunakan metode Weighted Product. Parameter yang dipertimbangkan antara lain: jumlah kunjungan (visit), durasi kunjungan (visit length), jumlah halaman yang dilihat (pageview), jumlah satu halaman yang dilihat pada satu kali kunjungan (bounce), kategori dari traffic source (medium), dan asal dari traffic (source). Berdasarkan proses perhitungan dan pengujian validasi maka didapatkan nilai kecocokan 100\%. Sehingga dapat disimpulkan sistem rekomendasi memiliki tingkat akurasi yang tinggi.
\end{abstract}

Kata kunci: Marketing, Weighted Product, Pelanggan, Rekomendasi, Web Analytics

\section{IMPLEMENTATION OF WEIGHTED PRODUCT TO PROVIDE CUSTOMER PROSPECT RECOMMENDATIONS}

\begin{abstract}
The success of a company in marketing the product or service offered is very dependent on marketing performance. Marketing activities currently developing are not only done conventionally through face-to-face contact with customers. One of the marketing activities done by companies is digital marketing. Digital marketing uses the Internet and the World Wide Web to approach customers. In achieving this goal, companies must adopt Web analytics, which is defined as "measurement, collection, analysis and reporting of Internet data for the purpose of understanding and optimizing Web use. By doing web analytics, marketing can recognize potential customers who often access the company's website. Unlike conventional marketing activities, the activity of recognizing website visitors becomes a particular difficulty. In this study deeper data will be extracted to see the behavior of website visitors from a company using the Weighted Product method. Parameters considered include: number of visits (visit length), number of visits (pageview), number of pages viewed at one visit (bounce), category of traffic source (medium), and origin from traffic (source). Based on the comparison of the results of the decision by applying the WP and the expert achieving a 100\% match value. So it can be concluded that the recommendation system has a high level of accuracy.
\end{abstract}

Keywords: Marketing, Weighted Product, Customer, Parameter, Web Analytics

\section{PENDAHULUAN}

Pada era persaingan bisnis saat ini, marketing menjadi ujung tombak pada suatu perusahan dalam menjalankan bisnis. Keberhasilan sebuah perusahaan dalam memasarkan produk atau jasa yang ditawarkan sangat tergantung dari kinerja marketing. Marketing merupakan serangkaian kegiatan yang meliputi 
perencanaan, penentuan harga barang jasa, promosi, dan distribusi kepada konsumen dan bisa memuaskan konsumen. Kegiatan marketing saat ini berkembang tidak hanya dilakukan secara kovensional melalui tatap muka langsung dengan pelanggan. Salah satu pemasaran yang dilakukan pada perusahaan adalah dengan digital marketing. Digital marketing menggunakan Internet dan World Wide Web untuk mendekati pelanggan. Hal ini telah dilakukan sekian lama untuk mendukung kemajuan perusahaan. Perusahaan internasional besar seperti Google, Facebook, Amazon, Alibaba, eBay dan Uber, yang belum pernah terdengar dua puluh tahun yang lalu, sekarang telah muncul sebagai pemain kunci dalam perekonomian modern (Kannan dan Li, 2017). Penjualan yang dilakukan melalui perangkat seluler telah meningkat dengan sangat cepat menjadi antara $22 \%$ dan $27 \%$ dari semua penjualan online(Rao, 2015; Malcolm, 2015). Perusahaan sekarang menyoroti pentingnya menciptakan "hubungan digital" dengan pelanggan (Phillips, 2015). Dengan semakin meningkatnya interaksi pelanggan dengan perusahaan melalui media digital, marketing telah menyadari kebutuhan untuk melacak interaksi serta mengukur performanya (Chaffey dan Patron, 2012). Untuk mencapai tujuan ini, perusahaan harus mengadopsi Web analytics, yang didefinisikan sebagai "pengukuran, pengumpulan, analisis dan pelaporan data Internet untuk tujuan memahami dan mengoptimalkan penggunaan Web (Analytics, 2008). Dengan melakukan web analytics, marketing dapat mengenali calon pelanggan yang sering mengakses website perusahaan. Penggunaan analisis web untuk mengukur performa digital marketing menjelaskan bahwa analisis web dapat menunjukkan sumber traffic website dan perilaku pengunjung selama mengunjungi website (Joel \& Heikki, 2015).

Tidak seperti kegiatan marketing konvensional, kegiatan mengenali pengunjung website menjadi kesulitan tersendiri. Hanya 1-2\% pengunjung website yang meninggalkan detail kontak, sisanya tidak diketahui asal usulnya. Tentu saja hal ini menyulitkan sales untuk melakukan kegiatan memasarkan produk mereka. Kegiatan tersebut menjadi kurang terarah dan tidak efektif.

Pada penelitian ini akan dilakukan penggalian data lebih dalam untuk melihat perilaku dari pengunjung website dari sebuah perusahaan. Selain itu akan ditentukan parameter yang dapat dijadikan dasar untuk menetukan pelanggan yang dikatakan sebagai pelanggan yang potensial. Dengan ini diharapkan perusahaan dapat lebih banyak menangkap pelanggan potensial (lead) yang selanjutnya dapat ditindaklanjuti oleh bagian sales. Semakin banyak lead yang diperoleh maka upaya marketing untuk mengelolanya juga bertambah, ini memungkinkan terjadinya human error. Pelanggan potensial yang memiliki aktifitas cukup intens dalam mengakses website perusahaan merupakan sebuah peluang untuk ditindak lanjuti. Dengan adanya aktifitas mengunjungi website merupakan sebuah indikasi adanya keminatan untuk membeli produk ataupun jasa yang ditawarkan. Sehingga apabila hal ini tidak ditindaklanjuti tentu saja merugikan perusahaan karena bisa jadi calon pelanggan tersebut tidak tahu yang harus dilakukan atau bahkan beralih ke perusahaan kompetitor.

Untuk menyelesaikan permasalahan tersebut maka diperlukan metode sistem pendukung keputusan untuk membantu perusahaan mengambil keputusan dengan cepat,tepat, dan konsisten. Banyak metode yang dapat digunakan untuk mengembangkan sistem pendukung keputusan, salah satunyanya adalah Weighted Product. Metode Weighted Product ini lebih efisien karena waktu yang dibutuhkan dalam perhitungan lebih singkat. Telah banyak penelitian yang dilakukan dengan Weighted Product dan mencapai akurasi yang tinggi . Pada penelitian ini akan diimplementasikan metode Weighted Product untuk memberikan rekomendasi prospek pelanggan kepada sales marketing berdasarkan beberapa parameter antara lain: jumlah kunjungan (visit), durasi kunjungan (visit length), jumlah halaman yang dilihat (pageview), jumlah satu halaman yang dilihat pada satu kali kunjungan (bounce), kategori dari traffic source (medium), dan asal dari traffic (source). Pada penelitian ini, lead yang diperoleh merupakan pengunjung sebuah website milik sebuah perusahaan nasional yang menyediakan peralatan kantor dan jasa layanan purna jual (after-sales service). Pengambilan lead akan dilakukan dengan memanggil API Google Analytics dan Leadfeeder. Dengan adanya sistem ini diharapkan dapat memberikan rekomendasi kepada tim marketing mengenai rating dari pelanggan potensial. Sehingga kegiatan marketing menjadi lebih terarah dan tepat sasaran.

\section{WEIGHTED PRODUCT}

Weighted product (WP) merupakan salah satu analisis keputusan multi-criteria decision making (MCDM) yang populer. Metode weighted product adalah metode yang menerapkan perkalian untuk menghubungkan atribut rating, dimana setiap atribut rating harus dipangkatkan dulu dengan bobot atribut yang bersangkutan.(Setyawan, Arini dan Akhlis, 2017). Dalam menerapakan WP memerlukan kriteria dan alternatif dalam perhitungannya. Alternatif adalah pilihan yang telah ditentukan sebelumnya yang kemudian akan diberikan bobot. Kriteria digunakan sebagai dasar acuan dalam proses menentukan alternatif tersebut. Pada saat menentukan kriteria juga ditentukan kelompok kriteria tersebut termasuk kriteria benefit atau kriteria cost. Apabila kriteria termasuk kriteria benefit maka kriteria akan memberikan keuntungan dimana semakin besar nilai akan semakin baik. Sedangkan kriteria cost merupakan kriteria biaya yang mana semakin besar nilainya akan semakin buruk. 
Kriteria yang telah ditentukan akan diberi bobot preferensi oleh pengambil keputusan. Tahap selanjutnya adalah melakukan perbaikan bobot sehingga total bobot bernilai 1, dengan cara yang ditunjukkan pada Persamaan 1.

$$
W_{j}=\frac{W_{j}}{\sum W_{j}}
$$

Tahap berikutnya adalah menentukan nilai vektor $\mathrm{S}$ dengan menggunakan rumus yang ditunjukkan pada Persamaan 2.

$$
S_{i}=\prod_{J=1}^{n} X_{i j} w_{j}
$$

Dimana:

S: Preferensi alternatif dianologikan sebagai vektorS $\mathrm{X}$ : Nilai kriteria

W: Bobot kriteria/subkriteria

i: Alternatif

j: Kriteria

$\mathrm{n}$ : Banyaknya kriteria

Nilai vektor $S$ yang telah didapatkan akan digunakan untuk menghitung preferensi $(V i)$ untuk menentukan ranking dengan rumus yang ditunjukkan pada Persamaan 3.

$$
V_{i}=\frac{\prod_{J=1}^{n} X_{i j} w_{j}}{\prod_{J=1}^{n}\left(X_{j *} w_{j}\right.}
$$

dimana :

$\mathrm{V}:$ Preferensi alternatif

$\mathrm{X}$ : Nilai Kriteria

W : Bobot kriteria/subkriteria

i : Alternatif

j : Kriteria

$\mathrm{n}$ : Banyaknya kriteria

* : Banyaknya kriteria yang telah dinilai

\section{LEAD GENERATION}

Penting bagi perusahaan untuk menciptakan hubungan dan membangun kepercayaan dengan pelanggan mereka. Hal ini perlu dilakukan untuk mendapatkan pelanggan baru ataupun mempertahankan pelanggan lama sehingga dapat kembali menggunakan produk/jasa yang ditawarkan oleh perusahaan tersebut. Lead merupakan kumpulan riwayat yang merepresentasikan ketertarikan pada produk atau layanan pada suatu perusahaan, terlepas dari apakah ketertarikan tersebut berasal dari calon pelanggan baru atau pelanggan lama (Monat, 2011). Lead generation merupakan salah satu aktifitas dalam pemasaran yang dilakukan sebuah perusahaan untuk menangkap perilaku calon pelanggan yang tertarik pada produk atau pelayanan perusahaan (Rothman, 2014). Lead generation dapat membantu perusahaan untuk mengidentifikasi pelanggan potensial dan proses pemasaran yang lebih terarah dan efektif. Lead generation dilakukan dengan melakukan analisis web pada digital marketing. Pada umumnya lead berupa daftar nama, alamat, nomor telepon, asal lokasi, dan hasil analisis web lainnya. Pada penelitian ini dilakukan analisis terhadap lead yaitu: jumlah kunjungan (visit), durasi kunjungan (visit length), jumlah halaman yang dilihat (pageview), jumlah satu halaman yang dilihat pada satu kali kunjungan (bounce), kategori dari traffic source (medium), dan asal dari traffic (source). Lead tersebut didapatkan dengan memanfaatkan LeedFeeder API untuk melakukan analisis pada studi kasus sebuah website perusahaan nasional yang bergerak pada bidang penjualan dan jasa alat-alat perkantoran. Lead yang diperoleh akan dianalisis dan dilakukang perangkingan untuk mendapatkan rekomendasi pelanggan yang prospek dengan menggunakan Weighted Product. Hasil rekomendasi yang diberikan nantinya dapat dimanfaatkan oleh sales untuk dapat ditindaklanjuti.

\subsection{Leadfeeder API}

Leadfeeder merupakan sebuah kakas bantu untuk menghasilkan prospek pelanggan atau dikenal dengan lead untuk perusahaan bussines to bussines yang didukung dengan Google Analytics (LeedFeeder, 2012). LeedFeeder memanfaatkan data dari Google Analytics yang telah didaftarkan dengan menggunakan token untuk melihat perilaku dari pengujung sebuah website perusahaan. Leadfeeder terhubung dengan Google Analytic dengan menggunakan API dan mengambil data mengenai pengunjung website. Leadfeeder API menggunakan desain RESTful yang berarti memiliki struktur URL yang intuitif dan merespon penggunaan HTTP (Leadfeeder, 2012). Dalam memberikan respons Leadfeeder API menggunakan format JSON.

Pemanfaatan leadfeeder ini membutuhkan akses akun berbayar dan telah memiliki akses ke profil website dari Google Analytic. Leadfeeder API membutuhkan token untuk dimasukkan kedalam sistem ketika ingin melakukan pengiriman request ke server.

\section{METODE PENELITIAN}

Terdapat beberapa tahap yang dilakukan pada penelitian ini. Gambar 1 menunjukan tahapan yang dilakukan yaitu mulai dari pengumpulan data, penentuan bobot, klasifikasi, menghitung $S i$ dan $V i$, dan perhitungan rating.

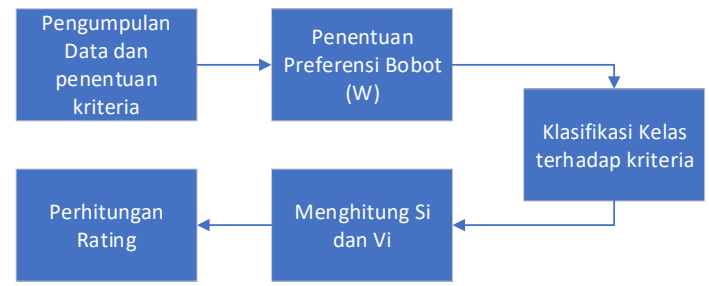

Gambar 1 Tahapan penelitian

Penjelasan lebih detail mengenai langkahlangkah penelitian dijelaskan pada subbab 4.1 sampai dengan 4.5. 


\subsection{Pengumpulan data dan penentuan kriteria}

Pada penelitian ini proses pengumpulan data menggunakan leadfeeder API dan google Analytics untuk mendapatkan data tracking pengunjung dari website perusahaan yang dijadikan studi kasus. Hasil tracking yang didapatkan berupa lead yang terdiri dari beberapa atribut yang menjelaskan identitas asal perusahaan yang mengunjungi seperti: nama perusahaan, tipe industri, lokasi perusahaan, alamat website, dan media sosial (linkedin). Selain itu terdapat data mengenai bagaimana cara dan ketertarikan pengunjung yang mengunjungi website seperti search engine yang digunakan, jumlah kunjungan, lama kunjungan, jumlah halaman yang dilihat, nilai bounce rate, dan halaman yang pertama kali dikunjungi. Data tersebut disimpan didalam database untuk memudahkan pengaksesan data. Selain itu telah dikembangkan sebuah sistem informasi untuk mendukung penelitian ini. Sistem informasi berupa dashboard sistem yang digunakan untuk mengolah data yang didapatkan dari leadfeeder dan google analytics. Gambar 2 dan 3 merupakan sistem informasi yang telah dikembangkan, sistem ini juga berfungsi untuk melakukan manajemen data prospek serta mendokumentasikan aktifitas apa saja yang telah dilakukan oleh sales terhadap data pelanggan.

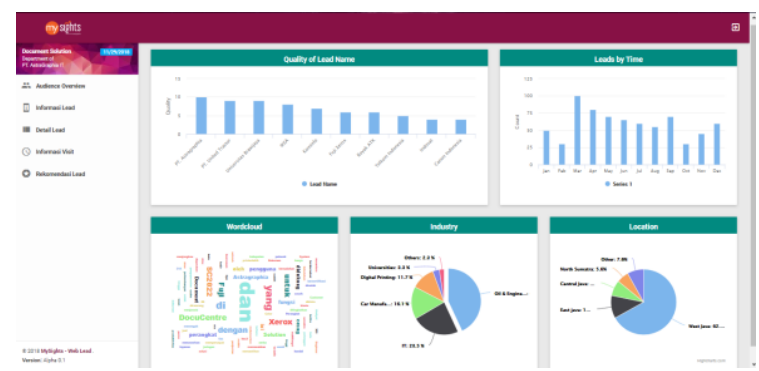

Gambar 2 Interface informasi dashboard sistem

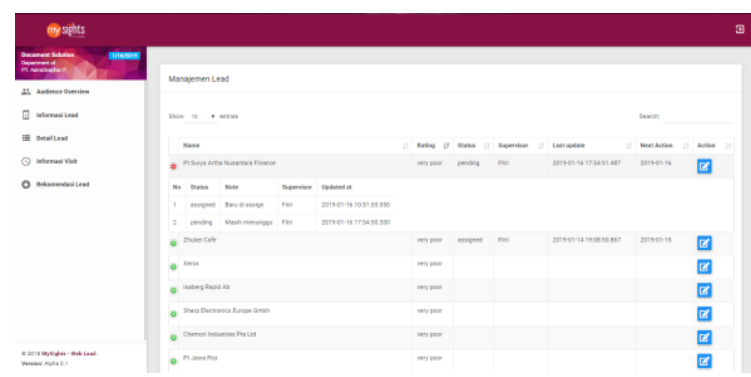

Gambar 3 Interface rekomendasi lead

Dalam memberikan rekomendasi prospek pelanggan dilakukan penentuan kriteria yang akan diperhitungkan. Pada Tabel 1 menunjukan kategori kriteria yang akan dipertimbangkan dalam analisis WP. Durasi visit, jumlah page yang dilihat, dan jumlah visit secara kesulurahan diyakini dapat merepresentasikan perilaku pengguna dalam digital marketing (Järvinen dan Karjaluoto, 2015). Bounce atau rasio pantulan adalah sesi satu halaman dibagi dengan semua sesi, atau persentase semua sesi di situs ketika pengguna hanya melihat satu halaman dan hanya memicu satu permintaan ke server Analytics (GoogleAnalytics, 2019). Semakin rendah rasio pantulan akan semakin baik.

\begin{tabular}{cccc} 
& & \multicolumn{2}{c}{ Tabel 1. Kategori Kriteria } \\
\hline No & Kode & Kriteria & Keterangan \\
\hline 1 & C1 & Visit Length & Durasi Visit \\
2 & C2 & Page View & Jumlah Page yang dilihat \\
3 & C3 & Bounce & Jumlah satu halaman \\
& C4 & Visit & Jang dilihat \\
4 & Jumlah Visit \\
5 & C5 & Medium & Kategori Source \\
6 & C6 & Source & Asal dari traffic \\
\hline
\end{tabular}

\subsection{Penentuan Bobot Preferensi}

Setelah menentukan kategori kriteria, langkah berikutnya adalah menentukan bobot preferensi. Penentuan bobot preferensi ditentukan oleh pemangku kepentingan dengan mempertimbangkan dengan kondisi dan kebutuhan dari perusahaan. Tabel 2 menunjukan bobot preferensi dari masing-masing kriteria. Sebelumnya telah dilakukan perbaikan bobot terlebih dahulu sehingga total bobot $(W j)=1$ dengan cara:

\begin{tabular}{cccc}
\multicolumn{4}{c}{ Tabel 2. Kategori Kriteria } \\
\hline No & Kode & Bobot & $\begin{array}{c}\text { Perbaikan Bobot } \\
(\mathbf{W j}=\mathbf{1})\end{array}$ \\
\hline 1 & C1 & 6 & 0.25 \\
2 & C2 & 5 & 0.20 \\
3 & C3 & 6 & 0.25 \\
4 & C4 & 3 & 0.125 \\
5 & C5 & 2 & 0.083 \\
6 & C6 & 2 & 0.083 \\
\hline
\end{tabular}

\subsection{Klasifikasi klas terhadap kriteria}

Dari setiap kategori yang ditentukan, kemudian diklasifikasikan sesuai nilai dari range yang diberikan. Tabel 3 menunjukan range terhadap variabel untuk masing-masing kriteria.

\begin{tabular}{ccc}
\multicolumn{2}{c}{ Tabel 3. Range nilai visit dan visit length } \\
\hline Criteria & Variable & Value \\
\hline Visit dan Visit & Very High $(>20)$ & 4 \\
Length & High $(11-20)$ & 3 \\
& Low (6-10) & 2 \\
Pageview & Very Low (0-5) & 1 \\
& Very High $(>10)$ & 4 \\
& High (4-10) & 3 \\
Total Bounce & Low (1-3) & 2 \\
& Very Low (0) & 1 \\
& Very High (>10) & 4 \\
Medium & High (7-10) & 3 \\
& Low (3-6) & 2 \\
& Very Low (0-2) & 1 \\
& Audience & 4 \\
Source & Organic & 3 \\
& Referral & 2 \\
& Other & 1 \\
& Direct & 5 \\
& Google & 4 \\
& fujixerox.com & 3 \\
& onlinesupport.fujixerox.com & 2 \\
\hline
\end{tabular}

\subsection{Perhitungan $S i$ dan $V i$}

Langkah berikutnya adalah menghitung dengan menggunakaan vektor Si. Kemudian Kemudian 
dilakukan perhitungan untuk vektor $V$ yang nantinya akan digunakan sebagai dasar acuan melakukan perangkingan. Tabel 4 menunjukan hasil perhitungan $S i$ dan $V i$ dengan mengambil sampel 12 perusahaan yang mengakses website.

\begin{tabular}{ccrc}
\multicolumn{5}{c}{ Tabel 4. Hasil perhitungan Si dan Vi } \\
\hline No & Perusahaan & Si & Vi \\
\hline 1 & Perusahaan 1 & 1.2968 & 0.00851 \\
2 & Perusahaan 2 & 1.4211 & 0.00932 \\
3 & Perusahaan 3 & 1.4376 & 0.00943 \\
4 & Perusahaan 4 & 2.0687 & 0.01357 \\
5 & Perusahaan 5 & 2.3220 & 0.01524 \\
6 & Perusahaan 6 & 2.1586 & 0.01417 \\
7 & Perusahaan 7 & 2.1609 & 0.01418 \\
8 & Perusahaan 8 & 1.5497 & 0.01017 \\
9 & Perusahaan 9 & 1.6419 & 0.01077 \\
10 & Perusahaan 10 & 1.5264 & 0.01001 \\
11 & Perusahaan 11 & 1.8703 & 0.01227 \\
12 & Perusahaan 12 & 1.8920 & 0.01241 \\
\hline
\end{tabular}

\subsection{Perhitungan Rating}

Setelah mendapatkan nilai $V i$, langkah berikutnya menentukan rating. Pada penelitian ini dilakukan pembagian rating menjadi 4 kelompok yaitu Sangat baik, Baik, Buruk, Sangat Buruk. Tabel 5 menunjukan pembagian rating beserta dengan range skala rating.

\begin{tabular}{ccc}
\multicolumn{3}{c}{ Tabel 5. Skala rating } \\
\hline No & Rating & Range Nilai Vi \\
\hline 1 & Sangat Baik & $0.0134-0.0152$ \\
2 & Baik & $0.0116-0.0134$ \\
3 & Buruk & $0.0098-0.0116$ \\
4 & Sangat Buruk & $0.0018-0.0098$ \\
\hline
\end{tabular}

\section{HASIL DAN PEMBAHASAN}

Berdasarkan rating yang telah ditentukan maka dari 12 sampel data tersebut dikelompokan berdasarkan nilai $V i$. Setelah itu dilakukan rekomendasi rangking prospek pelanggan untuk membantu sales menentukan prospek pelanggan. Tabel 6 menunjukan hasil perangkingan dengan menggunakan WP.

Tabel 6. Hasil rekomendasi

\begin{tabular}{clrl}
\hline $\begin{array}{c}\text { Rang } \\
\text { king }\end{array}$ & Perusahaan & \multicolumn{1}{c}{ Vi } & \multicolumn{1}{c}{ Rating } \\
\hline 1 & Perusahaan 5 & 0.015242 & Sangat Baik \\
2 & Perusahaan 7 & 0.014185 & Sangat Baik \\
3 & Perusahaan 6 & 0.01417 & Sangat Baik \\
4 & Perusahaan 4 & 0.013579 & Sangat Baik \\
5 & Perusahaan 12 & 0.01242 & Baik \\
6 & Perusahaan 11 & 0.012277 & Baik \\
7 & Perusahaan 9 & 0.010778 & Buruk \\
8 & Perusahaan 8 & 0.010173 & Buruk \\
9 & Perusahaan 10 & 0.01002 & Buruk \\
10 & Perusahaan 3 & 0.00943 & Sangat Buruk \\
11 & Perusahaan 2 & 0.00932 & Sangat Buruk \\
12 & Perusahaan 1 & 0.00851 & Sangat Buruk \\
\hline
\end{tabular}

Perusahaan 5 memiliki nilai $V i=0.015242$ dan tergolong kedalam kategori sangat baik. Hal ini dikarenakan Perusahaan 5 memiliki bobot visit length $=4, \quad$ pageview $=2, \quad$ bounce $=1, \quad$ visit $=1$, medium $=3$, source $=4$. Dengan bobot tersebut menjadikan perusahaan 5 direkomendasikan pada urutan 1 sehingga memiliki prospek paling tinggi apabila ditindak lanjuti oleh bagian sales. Tidak demikian dengan perusahaan 3 yang memiliki nilai $\mathrm{Vi}=0.00943$ dan tergolong ke dalam kategori sangat buruk. Perusahaan 3 memiliki bobot visit length $=1$, pageview $=3, \quad$ bounce $=1, \quad$ visit $=1, \quad$ medium $=1$, source $=5$. Sehingga pada hasil perangkingan berada pada urutan ke-10.

Pada penelitian ini dilakukan pengujian validasi hasil perangkingan oleh sistem dengan hasil dari ahli. Hasil pengujian dapat dilihat pada Tabel 7.

Tabel 7. Pengujian Validasi

\begin{tabular}{clccc}
\hline No & Perusahaan & $\begin{array}{c}\text { Urutan } \\
\text { Sistem }\end{array}$ & $\begin{array}{c}\text { Urutan } \\
\text { Ahli }\end{array}$ & $\begin{array}{c}\text { Kecocok } \\
\text { an }\end{array}$ \\
\hline 1 & Perusahaan 5 & 1 & 1 & Cocok \\
2 & Perusahaan 7 & 2 & 2 & Cocok \\
3 & Perusahaan 6 & 3 & 3 & Cocok \\
4 & Perusahaan 4 & 4 & 4 & Cocok \\
5 & Perusahaan 12 & 5 & 5 & Cocok \\
6 & Perusahaan 11 & 6 & 6 & Cocok \\
7 & Perusahaan 9 & 7 & 7 & Cocok \\
8 & Perusahaan 8 & 8 & 8 & Cocok \\
9 & Perusahaan 10 & 9 & 9 & Cocok \\
10 & Perusahaan 3 & 10 & 10 & Cocok \\
11 & Perusahaan 2 & 11 & 11 & Cocok \\
12 & Perusahaan 1 & 12 & 12 & Cocok \\
\hline
\end{tabular}

Berdasarkan proses perhitungan dan pengujian validasi maka didapatkan nilai kecocokan $100 \%$. Sehingga dapat disimpulkan sistem rekomendasi memiliki tingkat akurasi yang tinggi.

\section{KESIMPULAN}

Berdasarkan hasil penelitian yang dilakukan, kesimpulan yang didapat antara lain:

1. Perhitungan rekomendasi prospek pelanggan dilakukan dengan melakukan analisis web dengan mempertimbakan parameter parameter antara lain: jumlah kunjungan (visit), durasi kunjungan (visit length), jumlah halaman yang dilihat (pageview), jumlah satu halaman yang dilihat pada satu kali kunjungan (bounce), kategori dari traffic source (medium), dan asal dari traffic (source).

2. Proses analisis web menggunakan Leed Feeder dan Google Analytics

3. Rekomendasi hasil perhitungan dengan menerapkan metode WP dibandingkan dengan ahli mencapai tingkat akurasi 100\%

\section{DAFTAR PUSTAKA}

ANALYTICS, W., 2008. Web Analytics Definitions Licensed under a Creative Commons Attribution-Noncommercial-No Derivative Works 3.0 US License. [daring] Tersedia pada: $<$ https://www.digitalanalyticsassociation.org/Fi 
les/PDF_standards/WebAnalyticsDefinitions.p df $>$.

CHAFFEY, D. DAN PATRON, M., 2012. From web analytics to digital marketing optimization: Increasing the commercial value of digital analytics. Journal of Direct, Data and Digital Marketing Practice, 14(1), hal.30-45.

GOOGLEANALYTICS, 2019. GoogleAnalytics. [daring] Tersedia pada: $<$ https://support.google.com/analytics/answer/1 009409?hl=id $>$ [Diakses 13 Mei 2019].

JÄRVINEN, J. DAN KARJALUOTO, H., 2015. The use of Web analytics for digital marketing performance measurement. Industrial Marketing Management, [daring] 50, hal.117127. Tersedia pada: $<$ http://dx.doi.org/10.1016/j.indmarman.2015.0 4.009>.

KANNAN, P.K. DAN LI, H. “Alice,” 2017. Digital marketing: A framework, review and research agenda. International Journal of Research in Marketing, [daring] 34(1), hal.22-45. Tersedia pada:

$<$ http://dx.doi.org/10.1016/j.ijresmar.2016.11.0 $06>$.

LEEDFEEDER, 2012. LeadFeader. [daring] Tersedia pada: <https://www.leadfeeder.com> [Diakses 20 Okt 2018].

MALCOLM, H., 2015. Cyber Monday clocks record sales as mobile sales surge. [daring] usatoday. Tersedia pada: $<$ https://www.usatoday.com/story/money/2015/ 12/01/cyber-monday-sales-results/76602534/> [Diakses 27 Apr 2019].

MONAT, J.P., 2011. Industrial sales lead conversion modeling. Marketing Intelligence and Planning, 29(2), hal.178-194.

PHILLIPS, E., 2015. Retailers scale up online sales distribution networks. The Wall Street Journal November 17, 2015. [daring] Tersedia pada: $<$ https://www.wsj.com/articles/retailers-scaleup-online-sales-distribution-networks1447792869> [Diakses 27 Apr 2019].

RAO, L., 2015. Online Shoppers Spent \$4.45 Billion On Black Friday And Thanksgiving | Fortune.com. [daring] Fortune. Tersedia pada: $<$ http://fortune.com/2015/11/28/black-fridaysales-2/> [Diakses 27 Apr 2019].

ROTHMAN, D., 2014. Lead Generation for Dummies. For Dummies.

SAVITHA, K. DAN CHANDRASEKAR, C., 2011. Vertical Handover decision schemes using SAW and WPM for Network selection in Heterogeneous Wireless Networks. Global Journal of Computer Science and Technology, [daring] 11(9), hal.19-24. Tersedia pada: $<$ http://arxiv.org/abs/1109.4490>.
SETYAWAN, A., ARINI, F.Y. DAN AKHLIS, I., 2017. Comparative Analysis of Simple Additive Weighting Method and Weighted Product Method to New Employee Recruitment Decision Support System (DSS) at PT. Warta Media Nusantara. Scientific Journal of Informatics, 4(1), hal.34-42.

WANG, M., LIU, S., WANG, S. DAN LAI, K.K., 2010. A weighted product method for bidding strategies in multi-attribute auctions. Journal of Systems Science and Complexity, 23(1), hal.194-208. 